\title{
CD58 polymorphisms associated with the risk of neuromyelitis optica in a Korean population
}

\author{
Jason Yongha Kim ${ }^{1+}$, Joon Seol Bae ${ }^{2 \dagger}, \mathrm{Ho} \mathrm{Jin} \mathrm{Kim}^{3}$ and Hyoung Doo Shin ${ }^{1,4^{*}}$
}

\begin{abstract}
Background: Neuromyelitis optica (NMO) is a serious inflammatory demyelinating disease (IDD), characterized by the inflammation and demyelination of optic nerves and spinal cords, which subsequently leads to the loss of function. In a previous genome-wide association study, cluster of differentiation 58 (CD58) region was found to be susceptible for the risk of multiple sclerosis (MS) in Caucasian, and the association between CD58 variants and MS was replicated in Americans. However, no study has been conducted to explore the possible association between CD58 and NMO yet. Thus, this study aimed to investigate the association of CD58 polymorphisms with the risk of NMO in a Korean population.

Methods: Using TaqMan assay, 6 single nucleotide polymorphisms (SNPs) were genotyped in 98 NMO patients and 237 normal controls $(N=336)$. Logistic regression analysis was conducted to find a possible association between CD58 polymorphisms and NMO.

Results: The analysis results showed that 6 variations (rs2300747, rs 1335532, rs 12044852, rs 1016140, CD58_ht1, and CD58_ht3) showed significant associations $\left(P=0.002 \sim 0.008\right.$, $\left.P^{\text {corr }}=0.01 \sim 0.04\right)$.

Conclusion: The genetic variations in CD58 may be associated with the susceptibility of NMO in a Korean population. Based on previous studies, we suspect that the A allele of rs2300747 may decrease CD58 RNA expression, thus increasing NMO risk. Also, we deduced that the G allele of rs 1016140 caused an increase of $T$ cell activity, which in turn eased the access of AQP4 antibody into central nervous system (CNS) and ultimately leading to NMO development.
\end{abstract}

Keywords: CD58, NMO, SNP, Haplotype

\section{Background}

Neuromyelitis optica (NMO), which belongs to inflammatory demyelinating diseases (IDDs), is caused by the demyelination of axons in optic nerves and spinal cords. Although NMO has similarities with multiple sclerosis (MS), previous studies reported that MS and NMO may have different etiology [1-3]. In MS, demyelination causes symptoms such as a loss of sensitivity, hypoesthesia, parenthesis, disturbance of vision such as double vision, and muscle weakness. On the other hand, a loss of vision and spinal cord function are the most significant symptoms in

\footnotetext{
* Correspondence: hdshin@sogang.ac.kr

${ }^{\dagger}$ Equal contributors

'Department of Life Science, Sogang University, 1 Shinsu-dong, Seoul 121-742, Republic of Korea

${ }^{4}$ Department of Genetic Epidemiology, SNP Genetics, Inc, Seoul, Republic of Korea

Full list of author information is available at the end of the article
}

NMO [1,2]. It is also known that the prevalence of MS is higher in Caucasians than Asians (1 4/100,000 in Asian vs. $30 \sim 150 / 100,000$ in Caucasian) [4,5]. Contrary to MS, the prevalence of NMO is higher in non-Caucasians including African, Hispanic, and Asian [6].

Previous studies have shown that IDDs are complex-trait diseases with both genetic and environmental factors. However, compared to MS, there have been far less studies on NMO. In our previous study, a genome-wide association study (GWAS) was conducted for NMO and MS, showing that the risk polymorphisms for NMO and MS were different from each other [7]. Another study conducted in our group has shown that SNPs in cluster of differentiation 6 (CD6) and tumor necrosis factor receptor superfamily member $1 A$ (TNFRSF1A) were associated with NMO, but not with MS [8]. These studies have shown that

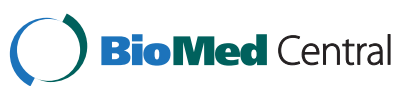

(c) 2014 Kim et al.; licensee BioMed Central Ltd. This is an Open Access article distributed under the terms of the Creative Commons Attribution License (http://creativecommons.org/licenses/by/2.0), which permits unrestricted use, distribution, and reproduction in any medium, provided the original work is properly credited. The Creative Commons Public Domain Dedication waiver (http://creativecommons.org/publicdomain/zero/1.0/) applies to the data made available in this article, unless otherwise stated. 
there are definite merits in conducting genetic association studies of NMO independently.

Cluster of Differentiation 58 (CD58), also known as lymphocyte function-associated antigen 3 (LFA-3), is one of cell adhesion molecules abundantly expressed on antigen presenting cells (APCs) [9]. Conjugation between CD58 and CD2 or LFA-2, expressed in T-cell, is crucial for T-cell activation [10]. Furthermore, the importance of T-cell in MS development is well documented in previous studies $[11,12]$. To date, several association studies were conducted between CD58 and IDDs since the first GWAS identified the gene's association with MS [13]. Follow-up studies have shown that CD58 SNPs such as rs2300747 and rs12044852 were associated with MS risk [14-18]. However, no study has looked into the association between CD58 and NMO. Therefore, in the present study, we have conducted association studies between CD58 polymorphisms and NMO in a Korean population.

\section{Methods}

\section{Subjects}

For genotyping of CD58 polymorphisms, 98 NMO patients and 237 controls were recruited. In order to study biologically homogenous population, all the patients showed both optic neuritis and longitudinally extensive transverse myelitis following the revised diagnostic criteria for NMO [19], and seropositive for aquaporin-4 antibody [20]. Anti-AQP4 antibodies were measured by using an enzyme-linked immunosorbent assay (ELISA) [21] and cell-based assay (CBA) with a commercial slide kit (Euroimmun, Luebeck, Germany) [22]. In addition, 237 healthy controls of Korean ethnicity were included $($ Age $=47.3(38.0-60.0)$, Female $/$ Male $=156 / 81)$ who did not have characteristics of inflammatory demyelinating diseases including NMO, classical MS, optic neuritis and transverse myelitis. The study protocol was approved by the Institutional Review Board of the National Cancer Center of Korea. We obtained agreement of each subject by written information before beginning the study. The information of the subjects for present study is summarized in Table 1. Detailed demographic and clinical characteristics of NMO patients were previously described elsewhere [23].

Table 1 Characteristics of study subjects

\begin{tabular}{lcc}
\hline & NMO & Control \\
\hline Number of subject & 98 & 237 \\
Sex (M/F) & $10 / 88$ & $81 / 156$ \\
Age (mean (min.-max.)) & $39.9(11-67)$ & $47.3(38-60)$ \\
Onset age (mean \pm Std) & $33.5 \pm 12.26$ & - \\
Duration (year, mean \pm Std) & $7.0 \pm 4.42$ & - \\
\hline
\end{tabular}

NMO, neuromyelitis optica.

\section{Single nucleotide polymorphism (SNP) selection and genotyping}

Six SNPs of CD58 were selected based on following conditions: (1) linkage disequilibrium (LD, minor allele frequency (> 0.05)), (2) locations (SNPs in exons were preferred), (3) previously reported SNP, (4) amino acid changes (non-synonymous SNPs were preferred). Genotype data of Asian (Chinese and Japanese) population from database of International HapMap Project (http:// hapmap.ncbi.nlm.nih.gov/) were used for selection. Then, the selected SNPs were genotyped in 99 NMO cases and 237 healthy controls using TaqMan assay on the ABI prism 7900HT sequence detection system (Applied Biosystems, USA). The TaqMan primer information was listed in Additional file 1: Table S1.

\section{Statistics}

LD was obtained using the HaploView software (version 4.2) from the Broad Institute (http://www.broadinstitute. org/mpg/haploview), with examination of Lewontin's D' $\left(\left|D^{\prime}\right|\right)$ and the LD coefficient $r^{2}$ between all pairs of biallelic loci [24]. P-values for Hardy-Weinberg equilibrium (HWE) were also calculated using the HaploView software. Haplotypes were first estimated using PHASE software [25], and then computed using Statistical Analysis System (SAS). Associations for NMO under logistic model were adjusted by age (continuous value) and sex (male $=0$, female $=1$ ) as covariates using SAS. In order to correct for the multiple testing error, the SNPSpD program (http:// gump.qimr.edu.au/general/daleN/SNPSpD/) was used, with the correction number of 4.5055. An in silico analysis was conducted by using Pupasuite 3.1 (http:// pupasuite.bioinfo.cipf.es/) [26].

\section{Results}

In the present study, we obtained the genotype information of 336 subjects comprised of 98 NMO patients and 237 healthy subjects. Detailed clinical information about the subjects is summarized in Table 1. A total of 6 SNPs was genotyped for the study, and their location, haplotypes, and LD map are displayed in Figure 1. For the present study, only the haplotypes with frequencies over 0.05 were used. In addition, genotype frequencies, heterozygosity, and P-values of HWE are shown in Additional file 1: Table S2. All of the polymorphisms in the study were in HWE except rs17426456, which was located in the exonic region. The comparisons of CD58 SNPs frequencies in Asian, Caucasian, and African populations showed that there were distinct differences among them (Additional file 1: Table S3). In order to compare the LD structures among populations, we have also drawn LD maps for African, Asian, and Caucasian in Additional file 1: Figure S1 (A, B, and C respectively). The results showed that the LD structure of Korean population was similar 


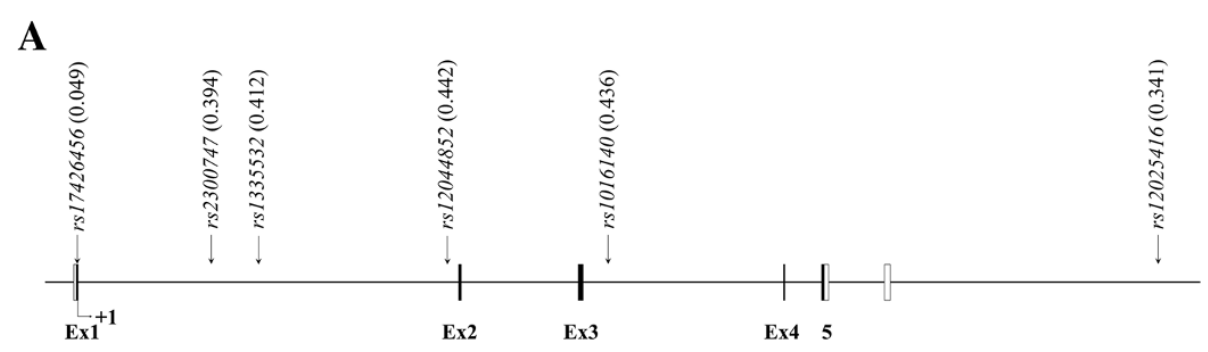

B

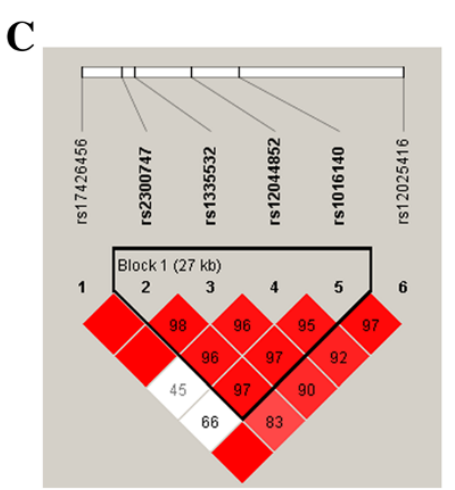

Figure 1 Schematic physical map, haplotypes and LD status of CD58 polymorphisms. (A) Polymorphisms identified in CD58. Coding exons are marked by shaded blocks and un-translated region (UTR) by white blocks. The LD coefficients $\left(r^{2}\right)$ are based on the genotypes of Korean samples. (B) Haplotypes of CD58 in the Korean population. Only those with frequencies over 0.05 are shown. Others contain rare haplotypes: AATCGC, GGCATC, AGCCTC, AGTCGT, GGCCGC, AGCCGT, AGCAGT, AATATC, AGCATT, AGTCGC, AGTATC, AACCGC, AATAGT, and AACATC. (C) LD coefficients (|D'| and $\left.r^{2}\right)$ among the selected SNPs based on the genotypes of whole study subjects in this study $(n=335)$.

with that of Asian, but slightly different from that of Caucasian. In contrast, the LD structure of African population was clearly distinct from other populations.

In order to examine the possible association between CD58 and NMO, we conducted association analysis between CD58 polymorphisms and NMO (Table 2). Statistical analyses revealed that 4 SNPs ( $r s 2300747$, rs1335532, rs12044852, and rs1016140) and 2 haplotypes (CD58_ht1 and CD58_ht3) showed significant associations with the risk of NMO $(P=0.002 \sim 0.008$, $\left.P^{\text {corr }}=0.01 \sim 0.04\right)$ (Table 2).

\section{Discussion}

In the present study, we have conducted logistic analysis to find a possible significant association between $C D 58$ polymorphisms and NMO in a Korean population. Previously, several studies have reported the associations of CD58 polymorphisms such as rs12044857, rs1335532 and $r s 2300747$, with MS $[13,17,18]$. Our results showed that the SNPs reported to be associated with MS (rs2300747, rs 13355332, and rs12044852) in previous studies $[15,17]$ were significantly associated with NMO as well. In addition, $r s 1016140$, which was not previously studied for MS or NMO, also showed a significant association in our results.
Table 2 Association analysis using CD58 polymorphisms and haplotypes with NMO risk

\begin{tabular}{lccccc}
\hline SNP/Haplotype & \multicolumn{2}{c}{ MAF } & OR (95\% Cl) & $P$ & $P^{c o r r}$ \\
\cline { 2 - 4 } & $\begin{array}{c}\text { Case } \\
(\mathbf{n}=\mathbf{9 8})\end{array}$ & $\begin{array}{c}\text { Control } \\
(\mathbf{n}=\mathbf{2 3 7})\end{array}$ & & & \\
\hline rs17426456 & 0.046 & 0.051 & $0.92(0.45-1.88)$ & 0.79 & NS \\
rs2300747 & 0.490 & 0.354 & $1.73(1.23-2.43)$ & 0.007 & 0.03 \\
rs1335532 & 0.520 & 0.367 & $1.87(1.33-2.63)$ & 0.002 & 0.01 \\
rs12044852 & 0.454 & 0.601 & $1.80(1.28-2.53)$ & 0.004 & 0.02 \\
rs1016140 & 0.535 & 0.395 & $1.76(1.25-2.47)$ & 0.005 & 0.02 \\
rs12025416 & 0.412 & 0.312 & $1.55(1.09-2.20)$ & 0.06 & NS \\
CD58_ht1 & 0.456 & 0.451 & $1.69(1.22-2.34)$ & 0.006 & 0.03 \\
CD58_ht2 & 0.234 & 0.281 & $1.52(1.06-2.17)$ & 0.12 & NS \\
CD58_ht3 & 0.089 & 0.063 & $2.13(1.19-3.84)$ & 0.008 & 0.04 \\
\hline
\end{tabular}

Logistic regression analyses were performed for calculating odds ratio $(95 \%$ confidential interval) and $P$-values for SNP sites and haplotypes. Age (continuous value) and sex (male $=0$, female $=1$ ) were adjusted by inclusion in logistic analysis as covariates. To obtain the optimal correction for multiple testing of single-nucleotide polymorphisms (SNPs) in linkage disequilibrium (LD) with each other, the effective number of independent marker loci (4.5055) in CD58 was calculated using the web based software SNPSpD (Http://genepi.qimr.edu.au/general/daleN/SNPSpD), on the basis of the spectral decomposition (SpD) of matrices of pairwise LD between SNPs. Significant associations $(<0.05)$ are italicized. MAF, minor allele frequency; $P^{\text {corr }}$, corrected $P$-value using multiple testing corrections; $\mathrm{OR}$, odds ratio; $\mathrm{Cl}$, confidence interval; NMO, neuromyelitis optica. 
Although there exist some differences between MS and NMO etiologies [27], the two diseases still share similar symptoms and onset mechanisms, in which the body's immune systems are misdirected to attack its own CNS. While CD58 polymorphisms had never been studied in association with $\mathrm{NMO}$, there were several studies which reported significant associations of CD58 variants with MS. Therefore, in Table 3, we listed the results of such studies and compared them with the present study result. The comparison showed that while the diseases and ethnicities were different between the previous MS studies and the present NMO study, the polymorphisms $r s 2300747(\mathrm{OR}=1.20-1.39$ in previous MS studies and 1.80 in the present study, $\mathrm{P}<0.05$ in all studies), $r$ s1335532 (1.28 in a previous MS study with Caucasian populations and 1.87 in the present study, $\mathrm{P}<0.05$ in both studies), and $r s 12044852$ (1.22 and 1.56 in previous MS studies $\left(\mathrm{P}=1.1 \times 10^{-6}\right.$ and 0.093 respectively) and 1.73 in the present study $(\mathrm{P}=0.007))$ were significantly associated with both MS and NMO in similar trends.

In order to further study the function of the CD58 SNPs, we have conducted in silico analysis of the 4 intronic SNPs associated with NMO. As a result, no SNPs were predicted to cause alternative splicing or be an exonic splicing enhancer or silencer (data not shown). However, previous reports suggest that there may be functional backgrounds on at least 2 SNPs, $r s 2300747$ and rs 1016140. In a recent study, the G allele of $r s 2300747$ was found to limit the MS inflammation by increasing the CD58 RNA expression [17]. In our study, we showed that the A allele of $r s 2300747$ was associated with the increased risk for NMO $\left(\mathrm{P}_{\text {cor. }}=0.03\right.$, OR $(95 \% \mathrm{CI})=1.73$ (1.23-2.43)). We suspect that the decreased CD58 RNA expression, caused by the A allele, may increase NMO risk as well, although further functional studies are required to confirm this notion.

A recent study has shown that $\mathrm{T}$ cell-mediated central nervous system (CNS) inflammation is a pre-requisite for the access of AQP4 antibody into CNS, an integral step in the development of NMO [30]. In a separate study, it was reported that $r s 1016140$ was associated with the decreased peak antibody level of hepatitis B virus and decreased $\mathrm{T}$ cell activity [31]. Another study also reported that the CD58 haplotype (rs1414275-rs11588376-rs1016140) might affect the response level of CD58 with T cell costimulatory molecules to decrease the T cell activity [32]. In the present study, the G allele of $r s 1016140$ was associated with the increased NMO risk. We suspect that the increased $\mathrm{T}$ cell activity caused by the $\mathrm{G}$ allele may lead to the more robust CNS inflammation, which in turn eases the access of AQP4 antibody into CNS, and ultimately leads to NMO development. Further studies would be needed to confirm our notion about the role of rs1016140 in the NMO etiology.

Although our study reports a potential association between CD58 polymorphisms and NMO, some limitations are present which should be addressed in the future. First, number of patients and controls enrolled in the study was relatively small, due to the rarity of the disease. This might have caused the low P-value of HWE for rs 17426456. Second, there was a disparity in the gender ratio, as there were far more female subjects than male subjects in the study. However, it has been reported that $\mathrm{NMO}$ is approximately 3 to 5 times more common in women than men [33]. In addition, association analysis was adjusted for gender to accommodate for this disparity. Lastly, functional study would be required to examine the actual effect of CD58 SNPs.

\section{Conclusions}

We have conducted association analyses between CD58 polymorphisms and NMO to find that 4 SNPs and 2 Haplotypes of CD58 were significantly associated with the increased risk of NMO. From previous studies, we have deduced the possible functional background of rs2300747 and rs1016140, but the roles of other

Table 3 Comparison of previous studies on CD58 - MS/NMO association

\begin{tabular}{|c|c|c|c|c|c|}
\hline \multirow[t]{3}{*}{ Reference } & \multirow[t]{3}{*}{ Study populations } & \multirow{3}{*}{$\begin{array}{l}\text { Study subjects } \\
\text { (case/control) }\end{array}$} & \multicolumn{3}{|c|}{ Study allele } \\
\hline & & & rs 12044852 & rs1335532 & $r s 2300747$ \\
\hline & & & $P$-value (OR) & $P$-value (OR) & $P$-value (OR) \\
\hline Hafler et al. (2007) [13] & US and UK (MS) & 2322/5418 (1540 family trios) & $1.9 \times 10^{-5}(1.24)$ & - & - \\
\hline Rubio et al. (2008) [16] & Australia (MS) & $1134 / 1265$ & $0.042(1.20)$ & - & - \\
\hline Bahlo et al. (2009) [18] & Australia, NZ, UK, and US (MS) & $3874 / 5723$ & - & $9.6 \times 10^{-8}(1.28)$ & - \\
\hline De Jager et al. (2009) [17]* & $\begin{array}{l}\text { US, UK, Belgium, Japanese, } \\
\text { Chinese, and Finland (MS) }\end{array}$ & 3558/4420 (1768 family trios) & - & - & $1.1 \times 10^{-6}(1.22)$ \\
\hline Brynedal et al. (2009) [28]* & Swedish (MS) & $1077 / 1217$ & $4.3 \times 10^{-4}(1.39)$ & - & - \\
\hline Qiu et al. (2013) [29] & Australia (MS) & $350 / 498$ & - & - & $0.093(1.56)$ \\
\hline Present study & Korean (NMO) & $99 / 237$ & $0.004(1.80)$ & $0.002(1.87)$ & $0.007(1.73)$ \\
\hline
\end{tabular}

*Since these studies had reversed minor and major alleles compared to the present study, we modified their results to conform to our results. Italicized $P$-values are values below 0.05 , which indicate significance. 
polymorphisms remain unknown. Our study is the first to find significant association between CD58 polymorphisms and NMO in a Korean population. However, further studies may be required to confirm the functional role of CD58 polymorphisms with NMO. We expect the results in the present study to provide a new insight on the role of CD58 in NMO and be helpful in developing new treatments for the diseases.

\section{Consent}

Written informed consent was obtained from the patient for the publication of this report and any accompanying images.

\section{Additional file}

Additional file 1: Table S1. Primer/probe information of CD58 SNPS. Table S2. Genotype frequencies of CD58 and P-value of deviations of Hardy-Weinberg equilibrium in a Korean population. Table S3. Minor allele frequencies of selected CD58 polymorphisms using data from HapMap project. Figure S1. Linkage disequilibrium plots for selected CD58 polymorphisms in different races. LD plots were based on data from International HapMap Project. (A) LD plot of African. (B) LD plot of Asian. (C) LD plot of Caucasian.

\section{Competing interests}

The authors declare that we have no competing interest.

\section{Authors' contributions}

JYK and JSB analyzed the data and wrote the manuscript. HJK supplied the raw data. HJK and HDS conceived the study. All authors read and approved the final manuscript.

\section{Authors' information}

Jason Yongha Kim and Joon Seol Bae are joint first authors.

\section{Acknowledgements}

This work was supported by Korea Science and Engineering Foundation (KOSEF) funded by the Korea government (MEST) (No. 2011-0004453). The biospecimens for this study were provided by National Biobank of Korea (KOBB-2010-19).

\section{Author details}

${ }^{1}$ Department of Life Science, Sogang University, 1 Shinsu-dong, Seoul 121-742, Republic of Korea. 'Laboratory of Translational Genomics, Samsung Genome Institute, Samsung Medical Center, 81 Irwon-RoGangnam-Gu, Seoul 135-710, Republic of Korea. ${ }^{3}$ Department of Neurology, National Cancer Center, 809 Madu 1-dong, Ilsandong-gu, Gyeonggi-do 410-769, Korea. ${ }^{4}$ Department of Genetic Epidemiology, SNP Genetics, Inc, Seoul, Republic of Korea.

Received: 19 November 2013 Accepted: 18 March 2014 Published: 24 March 2014

\section{References}

1. Weinshenker BG, Wingerchuk DM, Nakashima I, Fujihara K, Lennon VA: OSMS is NMO, but not MS: proven clinically and pathologically. Lancet Neurol 2006, 5(2):110-111.

2. Wingerchuk DM, Hogancamp WF, O'Brien PC, Weinshenker BG: The clinical course of neuromyelitis optica (Devic's syndrome). Neurology 1999, 53(5):1107-1114.

3. Argyriou AA, Makris N: Neuromyelitis optica: a distinct demyelinating disease of the central nervous system. Acta Neurol Scand 2008, 118(4):209-217.

4. Kim NH, Kim HJ, Cheong HK, Kim BJ, Lee KH, Kim EH, Kim EA, Kim S, Park MS, Yoon WT: Prevalence of multiple sclerosis in Korea. Neurology 2010, 75(16):1432-1438.
5. Rosati G: The prevalence of multiple sclerosis in the world: an update. Neurol Sci 2001, 22(2):117-139.

6. Jacob A, Matiello M, Wingerchuk DM, Lucchinetti CF, Pittock SJ, Weinshenker BG: Neuromyelitis optica: changing concepts. J Neuroimmunol 2007, 187(1-2):126-138.

7. Kim HJ, Park HY, Kim E, Lee KS, Kim KK, Choi BO, Kim SM, Bae JS, Lee SO, Chun JY, Park TJ, Cheong HS, Jo I, Shin HD: Common CYP7A1 promoter polymorphism associated with risk of neuromyelitis optica. Neurobiol Dis 2010, 37(2):349-355.

8. Park TJ, Kim HJ, Kim JH, Bae JS, Cheong HS, Park BL, Shin HD: Associations of CD6, TNFRSF1A, and IRF8 polymorphisms with risk of inflammatory demyelinating diseases. Neuropathol Appl Neurobiol 2013, 39(5):519-530.

9. Barbosa JA, Mentzer SJ, Kamarck ME, Hart J, Biro PA, Strominger JL, Burakoff SJ: Gene mapping and somatic cell hybrid analysis of the role of human lymphocyte function-associated antigen-3 (LFA-3) in CTL-target cell interactions. J Immunol 1986, 136(8):3085-3091.

10. Wang JH, Smolyar A, Tan K, Liu JH, Kim M, Sun ZY, Wagner G, Reinherz EL: Structure of a heterophilic adhesion complex between the human CD2 and CD58 (LFA-3) counterreceptors. Cell 1999, 97(6):791-803.

11. Seboun E, Robinson MA, Doolittle TH, Ciulla TA, Kindt TJ, Hauser SL: A susceptibility locus for multiple sclerosis is linked to the T cell receptor beta chain complex. Cell 1989, 57(7):1095-1100.

12. Hockertz MK, Paty DW, Beall SS: Susceptibility to relapsing-progressive multiple sclerosis is associated with inheritance of genes linked to the variable region of the TcR beta locus: use of affected family-based controls. Am J Hum Genet 1998, 62(2):373-385.

13. Hafler DA, Compston A, Sawcer S, Lander ES, Daly MJ, De Jager PL, de Bakker PI, Gabriel SB, Mirel DB, Ivinson AJ, Pericak-Vance MA, Gregory SG, Rioux JD, McCauley JL, Haines JL, Barcellos LF, Cree B, Oksenberg JR, Hauser SL: Risk alleles for multiple sclerosis identified by a genomewide study. N Engl J Med 2007, 357(9):851-862.

14. Hoppenbrouwers IA, Aulchenko YS, Janssens AC, Ramagopalan SV, Broer L, Kayser M, Ebers GC, Oostra BA, van Duijn CM, Hintzen RQ: Replication of CD58 and CLEC16A as genome-wide significant risk genes for multiple sclerosis. J Hum Genet 2009, 54(11):676-680.

15. Coustet B, Agarwal SK, Gourh P, Guedj M, Mayes MD, Dieude P, Wipff J, Avouac J, Hachulla E, Diot E, Cracowski JL, Tiev K, Sibilia J, Mouthon L, Frances C, Amoura Z, Carpentier P, Meyer O, Kahan A, Boileau C, Arnett FC, Allanore $Y$ : Association study of ITGAM, ITGAX, and CD58 autoimmune risk loci in systemic sclerosis: results from 2 large European Caucasian cohorts. J Rheumatol 2011, 38(6):1033-1038.

16. Rubio JP, Stankovich J, Field J, Tubridy N, Marriott M, Chapman C, Bahlo M Perera D, Johnson LJ, Tait BD, Varney MD, Speed TP, Taylor BV, Foote SJ, Butzkueven H, Kilpatrick TJ: Replication of KIAA0350, IL2RA, RPL5 and CD58 as multiple sclerosis susceptibility genes in Australians. Genes Immun 2008, 9(7):624-630.

17. De Jager PL, Baecher-Allan C, Maier LM, Arthur AT, Ottoboni L, Barcellos L, McCauley JL, Sawcer S, Goris A, Saarela J, Yelensky R, Price A, Leppa V, Patterson N, de Bakker PI, Tran D, Aubin C, Pobywajlo S, Rossin E, Hu X, Ashley CW, Choy E, Rioux JD, Pericak-Vance MA, Ivinson A, Booth DR, Stewart GJ, Palotie A, Peltonen L, Dubois B, et al: The role of the CD58 locus in multiple sclerosis. Proc Natl Acad Sci U S A 2009, 106(13):5264-5269.

18. Bahlo M, Booth DR, Broadley SA, Brown MA, Foote SJ, Griffiths LR, Kilpatrick TJ, Lechner-Scott J, Moscato P, Perreau VM, Rubio JP, Scott RJ, Stankovich J, Stewart GJ, Taylor BV, Wiley J, Clarke G, Cox MB, Csurhes PA, Danoy P, Drysdale K, Field J, Greer JM, Guru P, Hadler J, McMorran BJ, Jensen CJ, Johnson $\sqcup$, McCallum R, Merriman M, et al: Genome-wide association study identifies new multiple sclerosis susceptibility loci on chromosomes 12 and 20. Nat Genet 2009, 41(7):824-828.

19. Wingerchuk DM, Lennon VA, Pittock SJ, Lucchinetti CF, Weinshenker BG: Revised diagnostic criteria for neuromyelitis optica. Neurology 2006, 66(10):1485-1489.

20. Wingerchuk DM, Lennon VA, Lucchinetti CF, Pittock SJ, Weinshenker BG: The spectrum of neuromyelitis optica. Lancet Neurol 2007, 6(9):805-815.

21. Kim W, Lee JE, Li XF, Kim SH, Han BG, Lee BI, Kim JK, Choi K, Kim HJ: Quantitative measurement of anti-aquaporin-4 antibodies by enzymelinked immunosorbent assay using purified recombinant human aquaporin-4. Mult Scler 2012, 18(5):578-586.

22. Jarius S, Probst C, Borowski K, Franciotta D, Wildemann B, Stoecker W, Wandinger KP: Standardized method for the detection of antibodies to 
aquaporin-4 based on a highly sensitive immunofluorescence assay employing recombinant target antigen. J Neurol Sci 2010, 291(1-2):52-56.

23. Kim SH, Kim W, Li XF, Jung IJ, Kim HJ: Clinical spectrum of CNS aquaporin4 autoimmunity. Neurology 2012, 78(15):1179-1185.

24. Barrett JC, Fry B, Maller J, Daly MJ: Haploview: analysis and visualization of LD and haplotype maps. Bioinformatics 2005, 21(2):263-265.

25. Stephens M, Smith NJ, Donnelly P: A new statistical method for haplotype reconstruction from population data. Am J Hum Genet 2001,

68(4):978-989.

26. Conde L, Vaquerizas JM, Dopazo H, Arbiza L, Reumers J, Rousseau F, Schymkowitz J, Dopazo J: PupaSuite: finding functional single nucleotide polymorphisms for large-scale genotyping purposes. Nucleic Acids Res 2006, 34(Web Server issue):W621-W625.

27. Pittock SJ, Weinshenker BG, Lucchinetti CF, Wingerchuk DM, Corboy JR, Lennon VA: Neuromyelitis optica brain lesions localized at sites of high aquaporin 4 expression. Arch Neurol 2006, 63(7):964-968.

28. Brynedal B, Bomfim IL, Olsson T, Duvefelt K, Hillert J: Differential expression, and genetic association, of CD58 in Swedish multiple sclerosis patients. Proc Natl Acad Sci U S A 2009, 106(23):E58. author reply E59.

29. Qiu W, Pham K, James I, Nolan D, Castley A, Christiansen FT, Czarniak P, Luo Y, Wu J, Garlepp M, Wilton S, Carroll WM, Mastaglia FL, Kermode AG: The influence of non-HLA gene polymorphisms and interactions on disease risk in a Western Australian multiple sclerosis cohort. J Neuroimmunol 2013, 261(1-2):92-97.

30. Misu T, Fujihara K: [Pathogenesis of neuromyelitis optica]. Nihon Rinsho 2013, 71(5):823-828.

31. Hennig BJ, Fielding K, Broxholme J, Diatta M, Mendy M, Moore C, Pollard AJ, Rayco-Solon P, Sirugo G, van der Sande MA, Waight P, Whittle HC, Zaman $S M$, Hill AV, Hall AJ: Host genetic factors and vaccine-induced immunity to hepatitis B virus infection. PLoS One 2008, 3(3):e1898.

32. Ryckman KK, Fielding K, Hill AV, Mendy M, Rayco-Solon P, Sirugo G, van der Sande MA, Waight P, Whittle HC, Hall AJ, Williams SM, Hennig BJ: Host genetic factors and vaccine-induced immunity to HBV infection: haplotype analysis. PLOS One 2010, 5(8):e12273.

33. Wingerchuk DM: Neuromyelitis optica. Int MS J 2006, 13(2):42-50.

doi:10.1186/1471-2377-14-57

Cite this article as: Kim et al:: CD58 polymorphisms associated with the risk of neuromyelitis optica in a Korean population. BMC Neurology 2014 14:57.

\section{Submit your next manuscript to BioMed Central and take full advantage of:}

- Convenient online submission

- Thorough peer review

- No space constraints or color figure charges

- Immediate publication on acceptance

- Inclusion in PubMed, CAS, Scopus and Google Scholar

- Research which is freely available for redistribution 